\title{
Water Permeability of Cochlear Outer Hair Cells: Characterization and Relationship to Electromotility
}

\author{
Inna A. Belyantseva, ${ }^{1}$ Gregory I. Frolenkov, ${ }^{1}$ James B. Wade, ${ }^{2}$ Fabio Mammano, ${ }^{3}$ and Bechara Kachar ${ }^{1}$ \\ 1Section on Structural Cell Biology, National Institute on Deafness and other Communication Disorders, National Institutes \\ of Health, Bethesda, Maryland 20892, 2Department of Physiology, University of Maryland School of Medicine, Baltimore, \\ Maryland 21201, and ${ }^{2}$ Laboratory of Biophysics and Istituto Nazionale di Fisica della Materia, International School for \\ Advanced Studies, Trieste, Italy, 34014
}

The distinguishing feature of the mammalian outer hair cells (OHCs) is to elongate and shorten at acoustic frequencies, when their intracellular potential is changed. This "electromotility" or "electromechanics" depends critically on positive intracellular pressure (turgor), maintained by the inflow of water through yet uncharacterized water pathways. We measured the water volume flow, $J_{v}$, across the plasma membrane of isolated guinea pig and rat $\mathrm{OHCs}$ after osmotic challenges and estimated the osmotic water permeability coefficient, $P_{f}$, to be $\sim 10^{-2} \mathrm{~cm} / \mathrm{sec}$. This value is within the range reported for osmotic flow mediated by the water channel proteins, aquaporins. $J_{v}$ was inhibited by $\mathrm{HgCl}_{2}$, which is known to block aquaporin-mediated water transport. $P_{f}$ values that were estimated for $\mathrm{OHCs}$ from neonatal rats were of the order of $\sim 2 \times 10^{-3} \mathrm{~cm} / \mathrm{sec}$, equivalent to that of membranes lacking water channel proteins. In an immunofluo- rescence assay we showed that an anti-peptide antibody specific for aquaporins labels the lateral plasma membrane of the $\mathrm{OHC}$ in the region in which electromotility is generated. Using patch-clamp recording, we found that water influx into the $\mathrm{OHC}$ is regulated by intracellular voltage. We also found that the most pronounced increases of the electromotility-associated charge movement and of the expression of $\mathrm{OHC}$ water channels occur between postnatal days 8 and 12, preceding the onset of hearing function in the rat. Our data indicate that electromotility and water transport in OHCs may influence each other structurally and functionally.

Key words: mechanosensory transduction; electromotility; water permeability; aquaporins; voltage-dependent capacitance; postnatal development; organ of Corti; patch clamp
Outer hair cell (OHC) electromotility, i.e., the ability of these mechanosensory cells to contract and elongate under the direct control of the transmembrane potential (for review, see Frolenkov et al., 1998a), provides a cycle-by-cycle mechanical feedback loop capable of distorting the organ of Corti and amplifying the intracochlear vibrations (Nobili et al., 1998). OHCs have a cylindrical shape, which results from the interplay between flexible tensile elements of a cortical cytoskeletal network that underlies the lateral plasma membrane (Holley et al., 1992) and the positive hydrostatic pressure (turgor) of the cytoplasm (Brownell, 1990). Cell turgor plays a critical role because it not only controls $\mathrm{OHC}$ electromotile responses (Shehata et al., 1991) but also has the potential to influence the mechanics of the organ of Corti by changing the resting length of the cell and pretension state.

Electromotility involves an ATP-independent (Kachar et al., 1986) voltage-driven (Iwasa and Kachar, 1989; Dallos et al., 1991) "motor" protein, densely packed within the lateral plasma membrane (Kalinec at al., 1992). The voltage-dependent conformational changes of this motor protein are detected as a fast translocation of electrical charge within the membrane (Gale and Ashmore, 1997). The conformational changes of the $\mathrm{OHC}$ molecular motors produce changes in the surface area of the membrane (Kalinec at al., 1992) resulting in changes of membrane tension, which in turn affect the charge movement associated with electromotility (Iwasa, 1993; Gale and Ashmore, 1994). Recently, both GLUT5, a sugar

\footnotetext{
Received June 27, 2000; revised Sept. 20, 2000; accepted Sept. 27, 2000.

F.M. was supported by grants from Istituto Nazionale di Fisica della Materia (Progetto di Ricerca Avanzata CADY) and Ministero dell'Università e Ricerca Scientifica. We thank Richard Chadwick and Ron Petralia for critical comments and helpful suggestions. We also thank Davida Streett for help in the initial phase of this study.

Correspondence should be addressed to Dr. Bechara Kachar, Section on Structural Cell Biology, National Institute on Deafness and other Communication Disorders, National Institutes of Health, Building 36, Room 5D15, Bethesda, MD 20892-4163. E-mail: kacharb@nidcd.nih.gov.

Copyright (C) 2000 Society for Neuroscience $0270-6474 / 00 / 208996-08 \$ 15.00 / 0$
}

transporter (Geleoc et al., 1999), and a novel protein, prestin (Zheng et al., 2000), have been proposed as candidates for the $\mathrm{OHC}$ voltage-dependent membrane motor protein.

Electromotility also modulates the OHC axial stiffness (Frolenkov et al., 1998b; He and Dallos, 1999), which in turn depends mainly on the stiffness of the plasma membrane (Tolomeo et al., 1996). Therefore, cell turgor, which sets the resting membrane tension, is a critical parameter in the control of the OHC electromechanics. In many cell types water passage is facilitated by watertransporting proteins named aquaporins (Verkman and Mitra, 2000). Despite the importance of turgor for OHC function, no evidence for aquaporins in OHCs has been published so far. Interestingly, however, some sulfhydryl reagents that are able to block water transport (Macey and Farmer, 1970) also inhibit electromotility (Kalinec and Kachar, 1993; Frolenkov et al., 1997).

The present study provides evidence that water enters the cell via water channel proteins that are present in the lateral plasma membrane in which the OHC motor proteins are located. The postnatal expression of these water channel proteins and the development of motility-associated charge movement were found to occur at the same period of time. Finally, the water influx into the $\mathrm{OHC}$ depended on intracellular voltage, suggesting the interdependence of OHC water transport and electromotility.

\section{MATERIALS AND METHODS}

Preparation of isolated OHCs. Sprague Dawley rats (Taconic, Germantown, $\mathrm{NY}$ ), either adult ( $30 \mathrm{~d}$ old and older; $120-150 \mathrm{gm}$ ) or pups ranging from postnatal day 0 (PD0) to PD 22, or adult guinea pigs were suffocated with carbon dioxide and decapitated according to National Institutes of Health Guidelines for Animal Use. Strips of the organ of Corti were dissected as described previously (Frolenkov et al., 1997) in a modified Leibowitz cell culture medium (L-15) containing the following inorganic salts (in $\mathrm{mM}$ ): $137 \mathrm{NaCl}, 5.4 \mathrm{KCl}, 1.3 \mathrm{CaCl}_{2}, 1.0 \mathrm{MgCl}_{2}, 1.0 \mathrm{Na}_{2} \mathrm{HPO}_{4}, 0.44 \mathrm{KH}_{2} \mathrm{PO}_{4}$, and $0.81 \mathrm{MgSO}_{4}, \mathrm{pH} 7.35$. Approximately $5 \mathrm{~mm}$ galactose was added to the L-15 solution to adjust the osmolality to $325 \mathrm{mOsm} / \mathrm{kg}$, using a vapor pressure osmometer (type 5500, Wescor, Logan, UT). After 15-20 min incubation with $1 \mathrm{mg} / \mathrm{ml}$ of collagenase type IV (Life Technologies, Rockville, MD) at room temperature, cells from the apical turn of the 
cochlea were dissociated by gentle reflux of the tissue through the needle of a Hamilton syringe (N. 705, 22 gauge). OHCs were placed in a laminar flow bath $(100 \mu \mathrm{l})$, with exchange of medium $(\sim 5 \mathrm{ml} / \mathrm{hr})$ by a pressurized perfusion system (BPS-4, ALA Scientific Instruments, Westbury, NY), and were maintained at room temperature $\left(22-24^{\circ} \mathrm{C}\right)$ throughout the experiments. The viability of selected OHCs visualized on the microscope slide was determined on the basis of the following morphological features: uniform cylindrical shape, basal location of the nucleus, and intact stereocilia.

Application of hypo-osmotic solutions. A puff pipette, pulled on a programmable puller (P87, Sutter Instruments, Novato, CA) from $1.0 \mathrm{~mm}$ outer diameter borosilicate glass (\#30-30-0, FHC, Bowdoinham, ME) to a tip diameter of $\sim 1-2 \mu \mathrm{m}$, was filled with an L-15 solution made 5 $\mathrm{mOsm} / \mathrm{kg}$ hypo-osmotic in relation to the main perfusate. To maintain the concentrations of all of the solutes except galactose, we made the perfusate from the same solution that was used for hypo-osmotic stimulation by simply adding the $5 \mathrm{~mm}$ galactose. At least 10 measurements of osmolality of these solutions were done before each experiment. Average values of osmolality of the main perfusate and hypo-osmotic solution were found to be $325 \pm 1$ and $320 \pm 1 \mathrm{mOsm} / \mathrm{kg}$, respectively. The puff pipette was placed $25-30 \mu \mathrm{m}$ from the lateral wall of the $\mathrm{OHC}$, and pressure $(10 \mathrm{kPa})$ was applied to its back by a pneumatic injection system (PLI-100, Medical Systems, Greenvale, NY) gated under software control. OHCs that moved away from the puff pipette during the application of the hypo-osmotic solution were discarded.

Off-line quantification of $\mathrm{OHC}$ length and diameter. $\mathrm{OHC}$ length and diameter changes were measured as described in Frolenkov et al. (1997). Briefly, OHCs were observed with a video camera on an inverted microscope equipped with a $100 \times, 1.3$ numerical aperture (NA) Plan apochromatic objective and differential interference contrast optics. For illumination we used a $100 \mathrm{~W}$ mercury vapor light source passing by infrared and $560 \mathrm{~nm}$ narrow-band interference filters. OHC images were recorded at video rate to an optical disk recorder (Panasonic TQ-3031F). Alternatively, two images/sec were saved to a computer hard drive by the Imaging Workbench software (Axon Instruments, Foster City, CA). Digitized images were analyzed off-line with the image-processing software National Institutes of Health Image (National Institutes of Health, Bethesda, MD). For movement quantification, a measuring rectangle ranging in length from 20 to $100 \mu \mathrm{m}$ and composed of $3-15$ rows of pixels was positioned parallel to the cell axis for measurement of the cell length and perpendicular to the cell axis for measurement of the cell diameter. The average intensity profile across the edges of the cell was calculated, and the number of points in the profile was increased 10 times by cubic spline interpolation. The equivalent resolution increase was from $\sim 5$ to $\sim 50$ pixels $/ \mu \mathrm{m}$. Steep changes in the intensity profile were observed at the edges of the cell. The position of the cell edge along the length of the measuring rectangle was determined as the point at which the intensity profile crossed a given threshold, which was set manually. Errors of this procedure result mainly from uncertainties in the positioning of the threshold and depend on the width of the diffraction halo surrounding the image of the cell. Repeated measurements of the same cell dimensions with all possible threshold settings showed that the error in the determination of the absolute values of OHC length and diameter was $\sim 1 \mu \mathrm{m}$ in our experimental conditions. The implemented procedure traced relative time changes of these values with much higher accuracy, as long as the threshold setting was held fixed for all images in a sequence. SDs of length and diameter measurements obtained during a 120 sec observation period in unstimulated OHCs $(n=$ $5)$ and in OHCs stimulated with a control pressure application of isotonic solution $(n=3)$ were in the range of $0.02-0.04 \mu \mathrm{m}$.

Measurements of the osmotic water permeability. Images of $\mathrm{OHCs}$ were monitored and recorded at a $2 \mathrm{~Hz}$ sampling rate before, during, and after stimulation with hypo-osmotic solutions. Off-line quantification of length $(L)$ and diameter $(D)$ changes was performed as explained above. Only cells with a well preserved cylindrical shape were analyzed. The diameter of the cell was measured at three separate locations: (1) just below the cuticular plate, (2) in the middle of the cell, and (3) just above the nucleus. Then these values were averaged for later calculations.

Assuming that the cell shape can be described as the juxtaposition of a cylinder of length $L-D / 2$ and a hemisphere of diameter $D$, the lateral surface area $S\left(\mu \mathrm{m}^{2}\right)$ was computed as:

$$
S=\pi D(L-D / 2)
$$

and the cell volume $V\left(\mu \mathrm{m}^{3}\right)$ as:

$$
V=\pi(D / 2)^{2} \cdot(L-D / 2)+(2 \pi / 3) \cdot(D / 2)^{3} .
$$

The volume flow $J_{v}=\mathrm{d} V / \mathrm{d} t\left(\mu \mathrm{m}^{3} / \mathrm{sec}\right)$ was estimated from the slope of a linear fit to the rising portion of the $V(t)$ trace (see Fig. $1 B$, bottom trace) after an osmotic challenge. Assuming that most of the water enters the cell through the lateral cell membrane, where the pan-aquaporin antibody labeling was most intense (see Results), the osmotic water permeability coefficient $P_{f}(\mathrm{~cm} / \mathrm{sec})$ was calculated finally as:

$$
P_{\mathrm{f}}=\frac{J_{\mathrm{v}}}{S \cdot V_{\mathrm{w}} \cdot \Delta C}
$$

where $V_{w}=18.5\left(\mathrm{~cm}^{3} / \mathrm{mol}\right)$ is the partial molar volume of water (Verkman, 2000). Because the osmolality (mOsm $/ \mathrm{kg}$ ) of a dilute solution equals approximately its osmolarity $(\mathrm{mOsm} / \mathrm{l})$, we assumed $\Delta C$, the difference of osmolarities between the perfusate and the hypo-osmotic solution, to be equal to $5 \mathrm{mOsm} / 1$.

Antibodies. The following antibodies specific for aquaporins (AQP) were used in this study: anti-AQP1 through anti-AQP9 from Chemicon (Temecula, CA), anti-AQP1 and anti-AQP2 from Alomone (Jerusalem, Israel), anti-MIP26 (gift of Dr. A. Chepelinsky, National Eye Institute, National Institutes of Health), and a new custom-made polyclonal antibody raised against a synthetic polypeptide homologous to a conserved region of the aquaporin amino acid sequences. To produce this "pan-aquaporin" antibody, we immunized three rabbits with glutaraldehyde and MBSconjugated synthetic peptide corresponding to an extracellular domain of the AQP2 [amino acids (aa) 182-203, CSMNPARSLAPAVVTGKFD DHW] containing the conserved NPA motif of the aquaporin protein family. A BLAST search showed that this sequence is specific for the aquaporin protein family. Two rabbits provided a high titer of the antibodies. Antibodies were affinity-purified with a column of agarose beads to which $2 \mathrm{mg}$ of the peptide was linked covalently (SulfoLink Kit, Pierce, Rockford, IL). This pan-aquaporin antibody positively identified in Western blots a purified fraction of AQP1 (gift of P. Agre, John Hopkins University, Baltimore, MD).

Immunocytochemistry. Pups and adult rats were decapitated after death by carbon dioxide. The bullae were removed, and the cochleae were perfused locally with $4 \%$ paraformaldehyde (Electron Microscopy Sciences, Fort Washington, PA) in PBS and incubated in this fixative for $1 \mathrm{hr}$. All incubations were performed at room temperature unless otherwise noted. The organ of Corti was dissected from the cochlear spiral in PBS with a fine needle. Samples were permeabilized in $0.5 \%$ Triton X-100 (Polysciences, Warrington, PA) for $30 \mathrm{~min}$ and then washed in PBS. To block nonspecific binding sites, we used 5\% normal goat serum (Life Technologies) and $2 \%$ bovine serum albumin (ICN Biomedicals, Aurora, $\mathrm{OH}$ ) in PBS for either $1 \mathrm{hr}$ at room temperature or overnight at $4^{\circ} \mathrm{C}$. Samples were incubated for $2 \mathrm{hr}$ in the primary antibodies at a concentration of $\sim 5 \mu \mathrm{g} / \mathrm{ml}$ in blocking solution. After several rinses in PBS the samples were incubated in the secondary antibody for $40 \mathrm{~min}$ (fluoresceinconjugated anti-rabbit IgG; Amersham, Arlington Heights, IL). Samples were mounted with the ProLong Antifade Kit (Molecular Probes, Eugene, OR). A number of controls were done to verify the specificity of the antibodies that were used in this study. No signal was detected when the primary antibody was preincubated for $1 \mathrm{hr}$ at room temperature with an excess of the immunizing peptide or when the secondary antibody was used alone. Samples were viewed with a 510 Zeiss Laser Scanning Confocal microscope or a Zeiss Axiophot microscope with $63 \times$ and $100 \times$ objectives $(\mathrm{NA}=1.4)$.

Immunoblotting. Tissues were placed in an ice-cold TBS, $\mathrm{pH} 7.5$, containing the following protease inhibitors: $1 \mu \mathrm{g} / \mathrm{ml}$ leupeptin, $1 \mu \mathrm{g} / \mathrm{ml}$ pepstatin, $4 \mathrm{~mm}$ EDTA, and $2 \mathrm{~mm}$ AMSF. Then tissues were homogenized ultrasonically. Proteins were extracted and denatured by boiling in SDS sample buffer for $5 \mathrm{~min}$. Proteins were separated on $4-20 \%$ gradient Tris-glycine minigel (Novex, San Diego, CA), transferred to the nitrocellulose membrane, incubated in a blocking solution (5\% dry milk in TBST) overnight, and stained with a primary antibody for $2 \mathrm{hr}$ at room temperature. After several washes the membrane was incubated in alkaline phosphatase-conjugated anti-rabbit secondary antibody diluted 1:12,000 (Promega, Madison, WI). Staining was developed by using 5-bromo-4chloro-3-indolyl-phosphate/nitroblue tetrazolium alkaline phosphatase substrate (Kirkegaard \& Perry Laboratories, Gaithersburg, MD).

Patch-clamp recording. Patch-clamp recordings were performed with an Axopatch 1D amplifier (Axon Instruments). Pipettes for whole-cell recordings were formed on a programmable puller (P87, Sutter Instruments, Novato, CA) from $1.0 \mathrm{~mm}$ outer diameter borosilicate glass (number 30-30-0; FHC, Bowdoinham, ME) and filled with an intracellular solution containing (in mM): $140 \mathrm{CsCl}, 2.0 \mathrm{MgCl}_{2}, 5.0$ EGTA, and 5 HEPES, $\mathrm{pH}$-adjusted to 7.2 with $\mathrm{CsOH}$ and brought to $325 \mathrm{mOsm} / \mathrm{kg}$ with D-glucose. Current and voltage were sampled at $100 \mathrm{kHz}$ with a standard laboratory interface (Digidata 1200A, Axon Instruments) controlled by pClamp 7.0 software (Axon Instruments). The uncompensated pipette resistance was typically 3-5 M $\Omega$ when measured in the bath. The access resistance did not exceed $15 \mathrm{M} \Omega$. Potentials were corrected off-line for the error caused by the access resistance and the liquid junction potential. Based on the given solution composition, the junction potential computed by the pClamp 7.0 software was $-4.9 \mathrm{mV}$.

Capacitance measurement. Measurements of the cell capacitance $C_{m}$ were performed by using the membrane test feature of the pClamp 7.0 acquisition software, which continuously delivered a test square wave of period $T=4 \mathrm{msec}$ to the cell through the patch-clamp amplifier. Unfortunately, the pClamp software accurately estimates parameters $R_{m}$ (cell membrane resistance), $R_{a}$ (pipette access resistance), and $C_{m}$ only if $R_{m} \gg$ $R_{a}$, a condition that was not always met. To circumvent this problem, we reversed off-line the pClamp algorithm to recover the original values for the time integral of the transient current, $Q$, and $R_{t}$ and recomputed $R_{m}$, $R_{a}$, and $C_{m}$ as explained in Frolenkov et al. (2000). The patch-clamp parameters were monitored continuously at a resolution of $25 \mathrm{~Hz}$ by 
averaging the responses to 10 positive and 10 negative consecutive test steps. The series resistance and capacitance compensation circuitry of the patch-clamp amplifier were not used. To determine the voltage dependence of $C_{m}$, we applied triangular voltage ramps, swinging the cell potential from $V_{h}-100 \mathrm{mV}$ to $V_{h}+160 \mathrm{mV}$ (where $V_{h}$ is the holding potential) in $6 \mathrm{sec}$. Measurements of the cell capacitance during test ramps were corrected for the voltage drop along the access resistance of the pipette and then fit with:

$$
C_{\mathrm{m}}(V)=C_{0}+4 C_{\max } \frac{\exp \left(-\left(V-V_{\mathrm{p}}\right) / W\right)}{\left[1+\exp \left(-\left(V-V_{\mathrm{p}}\right) / W\right)\right]^{2}},
$$

which is the derivative of a Boltzmann function. $C_{0}$ is the linear (voltageindependent) capacitance, $C_{\max }$ is the maximum nonlinear capacitance, $V$ is the potential at the peak of $C_{m}(V)$, and $W=k_{\mathrm{B}} T / z e$ is a constant. The latter is a measure of the sensitivity of the nonlinear charge displacement to potential, expressed in terms of a charge of valence $z$ moving from the inner to the outer aspect of the plasma membrane. $k_{\mathrm{B}}$ is Boltzmann's constant, $T$ is absolute temperature, and $e$ is the electron charge.

The voltage-independent fraction of the cell capacitance scales linearly with the overall surface area of the cell. However, the nonlinear voltagedependent fraction of the cell capacitance is proportional to the area of the lateral membrane surface where the putative motor elements are located (Huang and Santos-Sacchi, 1993). Therefore, to compare the data obtained from different cells, the nonlinear voltage-dependent capacitance was divided by the area of the lateral plasma membrane to yield the specific nonlinear voltage-dependent capacitance of the lateral plasma membrane:

$$
\chi_{\mathrm{m}}(V)=\left(C_{\mathrm{m}}(V)-C_{0}\right) /[\pi D(L-D / 2)],
$$

(in $\mu \mathrm{F} / \mathrm{cm}^{2}$ ), where $L$ is the cell length and $D$ is the diameter. To estimate the density of charge movement (in $e^{-} / \mu \mathrm{m}^{2}$ ), we computed:

$$
\int_{-\infty}^{+\infty} \chi_{\mathrm{m}}(V) d V,
$$

by numerical integration.

\section{RESULTS}

\section{Effect of hypo-osmotic challenges on the volume of isolated OHCs}

The osmotic water permeability coefficient $P_{f}(\mathrm{~cm} / \mathrm{sec})$ is the critical parameter that is used to characterize the water transport properties of a defined barrier. It is measured from the volume flow, $J_{v}$, produced by water flux across the barrier in response to a specified osmotic gradient or hydrostatic driving force. At $25-37^{\circ} \mathrm{C}$, $P_{f}<5 \times 10^{-3} \mathrm{~cm} / \mathrm{sec}$ is consistent with simple water diffusion through lipid bilayers, whereas $P_{f}$ of the order of $10^{-2} \mathrm{~cm} / \mathrm{sec}$ suggests the involvement of water channels (Verkman, 2000).

In our experiments, performed at room temperature $\left(21-25^{\circ} \mathrm{C}\right)$, pressure application of hypo-osmotic solutions to the lateral wall of isolated OHCs induced cell swelling. Volume changes were derived from the simultaneous measurement of the (decreasing) length $L$ and (increasing) diameter $D$ (Fig. $1 A, B$ ) of the cell (see Materials and Methods). Computing the water permeability coefficient $P_{f}$ from the interpolated volume flow $J_{v}$ (Fig. $1 B$, dashed line) of adult guinea pig OHCs yielded values in the range of 9.1-14.7 $\times$ $10^{-3} \mathrm{~cm} / \mathrm{sec}\left(11.1 \pm 0.9 \times 10^{-3} \mathrm{~cm} / \mathrm{sec}\right.$, mean $\left.\pm \mathrm{SE} ; n=5\right) . P_{f}$ values of adult rat $\mathrm{OHCs}$ were $4.8-19.6 \times 10^{-3} \mathrm{~cm} / \mathrm{sec}(9.7 \pm$ $\left.1.1 \times 10^{-3} \mathrm{~cm} / \mathrm{sec} ; n=17\right)$. Osmotically evoked volume changes were inhibited by $78 \pm 16 \%(n=3)$ in the presence of $\mathrm{HgCl}_{2}(1$ mM; Fig. $1 C$ ), which is known to inhibit at similar concentrations the water transport mediated by a number of aquaporins (Folkesson et al., 1994; Verkman et al., 1996). Higher concentrations of $\mathrm{HgCl}_{2}$ (2 and $5 \mathrm{~mm}$ ) completely suppressed the osmotically evoked volume changes.

To determine where along the $\mathrm{OHC}$ the water permeability responses are more pronounced, we moved the puffing pipette to the three different positions indicated in Figure $1 D$. The largest volume changes were induced by delivery of the hypo-osmotic solution to the lateral portion of the cell wall as compared with applications directed to the apical or basal poles of the OHC (Fig. 1D).

In rats younger than PD10, $P_{f}$ was $2.2 \pm 0.5 \times 10^{-3} \mathrm{~cm} / \mathrm{sec}(n=$ 16 ), which is in the range measured for lipid bilayers (Fettiplace and Haydon, 1980). Water permeability increased rapidly between
PD11 and PD12, reaching values typical for adult animals at approximately PD15 (Fig. 1E).

\section{Labeling of cochlear tissue with antibodies raised against the aquaporin family}

These relatively large values of $P_{f}$ in OHCs of adult animals and the inhibition of water transport by $\mathrm{HgCl}_{2}$ suggested the involvement of water channels. To test this hypothesis, we did an immunocytochemistry screening of organ of Corti tissues with antibodies specific to each of the known mammalian aquaporins (AQP0AQP9). Consistent with previous reports (Stankovic et al., 1995; Takumi et al., 1998; Beitz et al., 1999), we found AQP1, AQP3, AQP4, and AQP5 in the plasma membrane of nonsensory cells of the organ of Corti (data not shown). Although none of these specific antibodies labeled the plasma membrane of $\mathrm{OHCs}$, a prominent staining was obtained with the polyclonal antibody raised against a synthetic peptide that reproduced the conserved region of the amino acid sequence of aquaporins (Fig. $2 A, B$ ). The labeling produced by this pan-aquaporin antibody extended along the OHC lateral wall, from just below the cuticular plate to the nuclear region (Fig. $2 F, G$ ). We also observed a comparatively dim labeling in the plasma membrane of inner hair cells and some of the nonsensory cells of the organ of Corti, which are known to express aquaporins (Stankovic et al., 1995; Takumi et al., 1998; Beitz et al., 1999). The strong OHC labeling also was obtained when the tissue was not permeabilized (Fig. 2C). This result confirms that the epitope, recognized by the pan-aquaporin antibody, indeed is located on an extracellular loop of the aquaporin. The labeling was eliminated when the antibody was preincubated with an excess of the immunizing peptide (Fig. 2D). Considering that the labeled lateral plasma membrane portion represents no less than $80 \%$ of the total surface area of the OHC, it is reasonable to assume that water influx through this region of the plasma membrane would be a major determinant of the cell turgor.

To confirm the ability of the pan-aquaporin antibody to recognize different aquaporins, we tested it in lens and kidney. We found immunolabeling in the plasma membrane of the external lens fibers and kidney collecting duct cells (data not shown) that correspond to known sites of aquaporin expression (Nielsen et al., 1993; Brown et al., 1995; Butkus et al., 1997),

Western blot analysis with the pan-aquaporin antibody revealed, as expected (Nielsen et al., 1993), multiple bands in the adult rat organ of Corti, kidney, and lens tissues. In the organ of Corti a major band of $\sim 58 \mathrm{kDa}$ was observed, together with several faint bands of higher molecular weight (Fig. $2 E$ ). The $58 \mathrm{kDa}$ band was barely visible in the neonatal organ of Corti tissue but appears as a distinct and robust band as early as PD 6, suggesting that this protein is expressed progressively during postnatal development, in agreement with the immunocytochemistry data (see below). The presence of other bands corresponding to proteins of different sizes is consistent with an ability of the pan-aquaporin antibody to detect the presence of different aquaporins (Fig. 2E). The highmolecular-weight bands are likely to represent dimers or tetramers of different aquaporin proteins (Butkus et al., 1997).

\section{Postnatal expression pattern of the proteins recognized by the pan-aquaporin antibody}

Figure 3 shows the developmental increase of expression of the proteins recognized by the pan-aquaporin antibody in the OHCs of the apical, middle, and basal turns of the organ of Corti. The earliest detection of immunofluorescence labeling was at the basal turn at PD3. Protein expression developed progressively from base to apex, reaching the middle turn at PD7 and the apical turn at PD9. The labeling intensity reached adult levels in all of the OHCs throughout the entire cochlea at PD12 (compare Figs. 2 and 3). This pattern of expression is consistent with structural and functional maturation of the rat organ of Corti proceeding from base to apex during the first 2 weeks after birth (Crowley and HeppReymond, 1966; Pujol et al., 1980; Uziel et al., 1981; Rubel, 1984). 

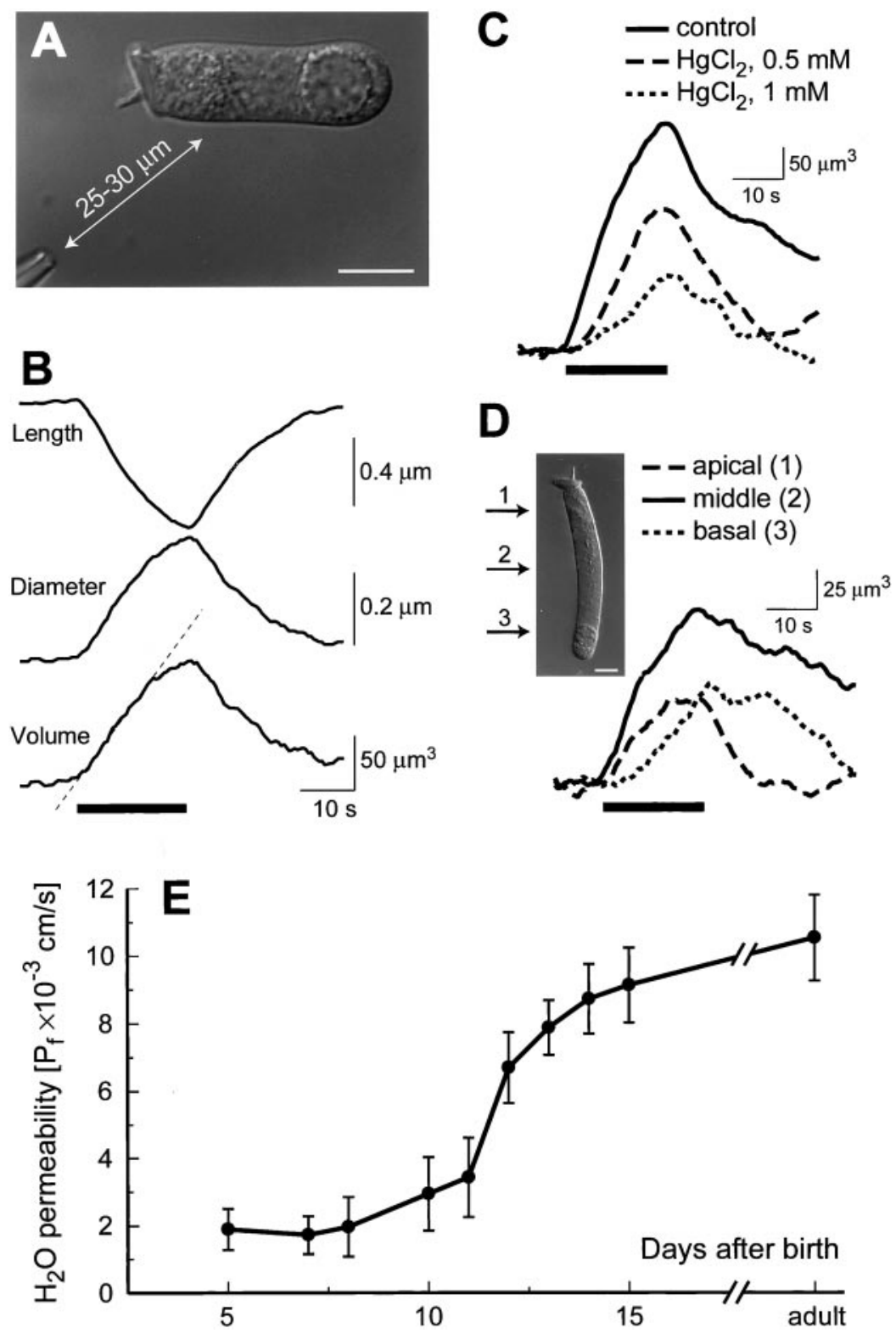

Figure 1. Characterization of water permeability in OHCs. $A$, Video image of an $\mathrm{OHC}$ from a 12-d-old rat showing the position of the puff pipette relative to the stimulated cell. Scale bar, $10 \mu \mathrm{m}$. $B$, Changes of cell length, diameter, and volume after the pressure application of a hypo-osmotic solution (320 $\mathrm{mOsm} / \mathrm{kg}$ ) to the cell in $A$. The solid horizontal bar indicates the timing of the solution application. The dashed line superimposed on the volume trace is a linear fit through the rising phase of the volume response. Line slope measures the speed of the volume increase. $C$, Volume changes of a different $\mathrm{OHC}$ from an adult rat evoked by a hypo-osmotic challenge before (solid line) and during two consecutive bath applications of the water transport inhibitor $\mathrm{HgCl}_{2}(0.5 \mathrm{~mm}$, dashed line; $1 \mathrm{~mm}$, dotted line). $D$, Volume changes of an 85- $\mu \mathrm{m}$-long guinea pig OHC (shown as inset) caused by the application of the hypoosmotic solution to the apical (dashed line), central (solid line), and basal (dotted line) portions of the cell. Arrows indicate the positions of the puff pipette. Scale bar, $10 \mu \mathrm{m}$. E, Developmental changes of the water permeability coefficient $\left(P_{f}\right)$ of $\mathrm{OHCs}$ isolated from the apical turn of the rat cochlea. Each point represents the mean $\pm \mathrm{SE}$ for several cells $(4 \leq n \leq 8)$ tested at each particular age.

\section{Postnatal development of the OHC electromotility}

Because the pan-aquaporin antibody recognized a protein highly expressed in the lateral plasma membrane of OHCs (Fig. $2 F, G$ ) where the putative $\mathrm{OHC}$ motor proteins are localized (Kalinec et al., 1992), we compared the postnatal development of water transport and electromotility in rat OHCs. The translocation of electrical charges across the membrane that accompanies electromotility imparts a bell-shaped dependence of membrane capacitance on transmembrane potential (Santos-Sacchi, 1991). In OHCs from the apical turn of the rat cochlea, electromotility and voltagedependent capacitance could be detected as early as PD5 (Fig. $4 A, B)$. In the PD0-PD4 rats the voltage dependence of capacitance could not be fit satisfactorily with a characteristic bell-shaped curve (data not shown). The steepest growth of the motility-associated charge movement was observed between PD8 and PD12 (Fig. 4C). This is the period when the auditory thresholds rapidly decrease toward values typical for adult rats (Crowley and Hepp-Reymond, 1966). At PD12 the OHCs showed robust electromotility and the characteristic bell-shaped voltage dependence of the capacitance (Fig. $4 A, B$ ). At PD17 the density of the motility-associated charge movement reached $6500 \pm 500 e^{-} / \mu \mathrm{m}^{2}(n=6)$, a value very close to the values measured for the OHCs from adult rats (Fig. $4 C$ ). The time course of the developmental changes of the charge movement density was similar to that of the permeability coefficient $P_{f}$ (compare Figs. $4 C$ and $1 E$ ).

\section{Osmotic volume flow in OHCs is voltage-dependent}

Figure 5 shows that, when $\mathrm{OHCs}$ were patch-clamped, the transient and reversible swelling of the cell produced by an osmotic challenge was a monotonically decreasing function of the transmembrane potential (Fig. 5C). This effect cannot be ascribed to deterioration of the cell turgor because prominent length changes were induced by voltage steps before and after the application of the hypoosmotic solution (Fig. $5 B$, third set of traces). Osmotically induced swelling of OHCs did not produce any significant ionic current (Fig. 5B, second set of traces). The constancy of the volume baseline trace preceding the osmotic challenge at any one potential (Fig. 5B, bottom) confirms that the voltage-driven length changes were accompanied by concurrent changes of the cell diameter at a constant volume.

\section{DISCUSSION}

\section{Osmotic water permeability of OHCs}

The values for the OHC osmotic water permeability, $P_{f}$, determined in our experiments were $9.7 \pm 1.1 \times 10^{-3}$ and $11.1 \pm 0.9 \times$ $10^{-3} \mathrm{~cm} / \mathrm{sec}$ for the adult rat and guinea pig, respectively. These 

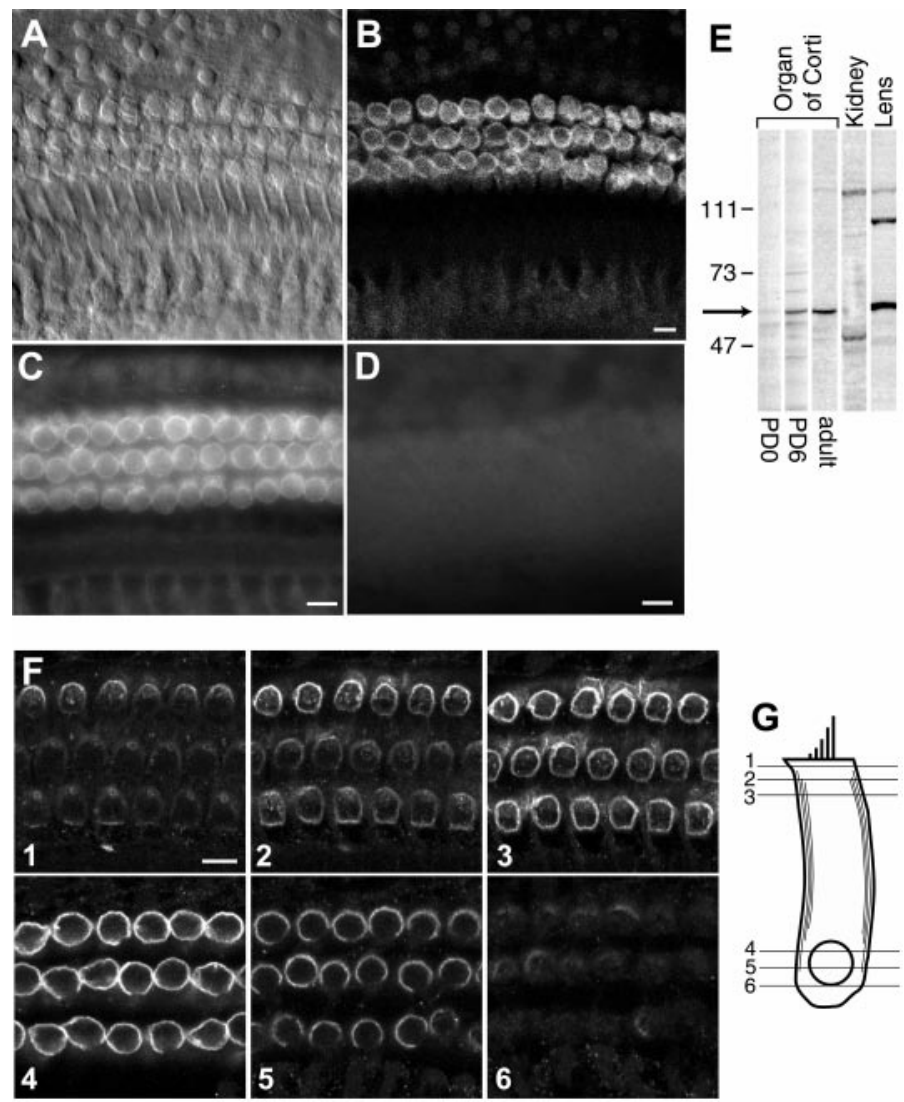

Figure 2. Immunolocalization of the antigen recognized by the panaquaporin antibody. $A$, Bright-field confocal image of the whole mount of the organ of Corti. $B$, Same confocal plane observed in epifluorescent illumination to show the immunolabeling reaction with the affinity-purified pan-aquaporin antibody. The sample was permeabilized with Triton X-100. $C$, Conventional fluorescent image of the nonpermeabilized sample immunolabeled with the pan-aquaporin antibody. $D$, Suppression of immunolabeling after preadsorption of the antibody with the immunizing peptide. $E$, Western blot analysis of the proteins recognized by the pan-aquaporin antibody in different tissues. Shown from left to right are the organ of Corti from rats of different age $(P D 0, P D 6$, adult), kidney, and lens of adult rat. The major $\sim 58 \mathrm{kDa}$ band is revealed in the organ of Corti (arrow). Multiple bands are seen in other tissues. $F$, Consecutive confocal optical sections $(0.7$ $\mu \mathrm{m}$ thickness, numbered 1-6) taken at 2.8, 4.2, and 5.6 $\mu \mathrm{m}$ below the cuticular plate (top row) and at 4.9,3.5, and $2.1 \mu \mathrm{m}$ from the base of the cell (bottom row). At intermediate positions along the length of the cell the antibody distinctly labeled the lateral wall of the $\mathrm{OHCs}$, producing annular fluorescence patterns similar to those shown in panels 3 and 4 . $G$, Schematic view of confocal sections shown in $F$. Scale bars, $10 \mu \mathrm{m}$.

values are more than one order of magnitude higher than the $0.1-0.5 \times 10^{-3} \mathrm{~cm} / \mathrm{sec}$ estimates previously reported (Ratnanather et al., 1996). However, these lower estimates were obtained by slow exchange of solutions in the bath (typical time to exchange $90 \%$ of the solution, $\sim 1.5 \mathrm{~min}$ ). We used fluid pressure application with a puff pipette to deliver hypo-osmotic media to the OHC with solution exchange time of $4.3 \pm 0.5 \mathrm{sec}$. This may account for the observed difference in recorded $P_{f}$ values. Most cells react to swelling with a complex regulatory response (Katz, 1995) called regulatory volume decrease (RVD). The characteristic time constant of RVD is $\sim 1-3$ min, and it involves the opening of swellingactivated conductance channels that allow ions and other osmolytes to flow out of the cell. OHCs have been shown to exhibit RVD (Crist et al., 1993). The RVD response of the OHC is likely to compromise the measurement of the coefficient $P_{f}$ when the duration of the hypo-osmotic challenge is comparable with the RVD time constant. We expected the RVD effect in our experiments to be insignificant because swelling duration did not exceed 25 sec. Our sensitive motion detection method also allowed us to minimize the degree of swelling by using a hypo-osmotic challenge of only -5 $\mathrm{mOsm} / \mathrm{kg}$ as compared with the previously used -25 and -45
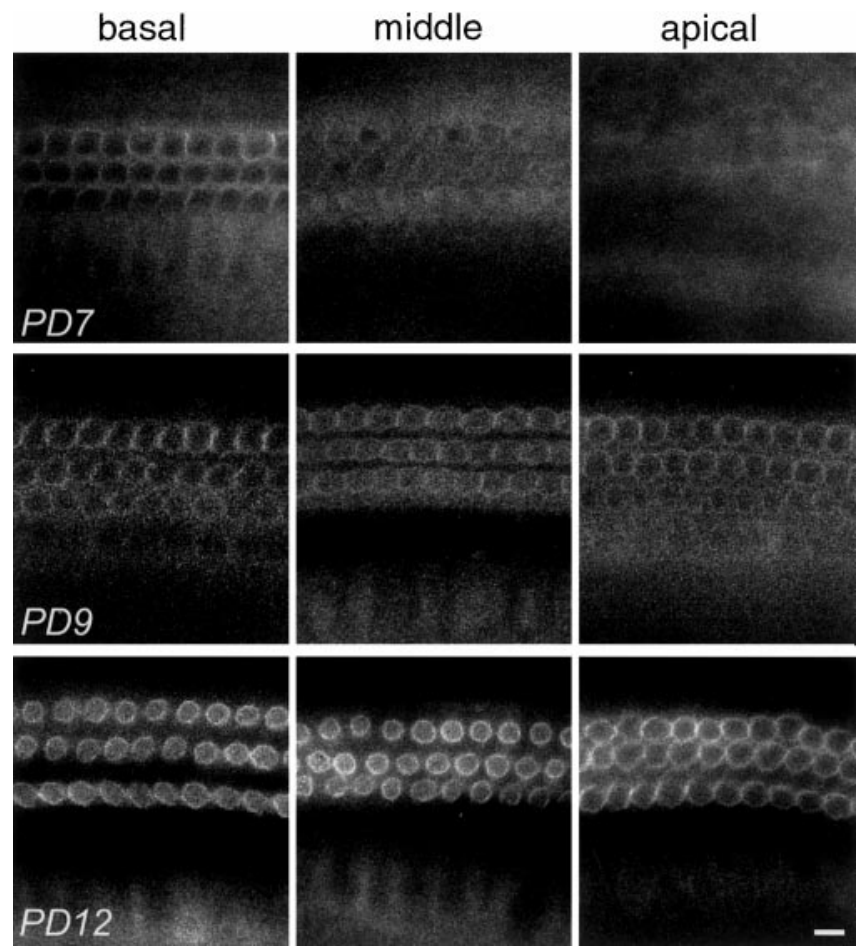

Figure 3. Postnatal development of protein expression revealed by the pan-aquaporin antibody. Organs of Corti of 7-d-old (PD7; top row), 9-d-old (PD9; middle row), and 12-d-old (PD12; bottom row) rats were separated into three segments (basal, middle, and apical) and processed simultaneously. Scale bar, $10 \mu \mathrm{m}$.
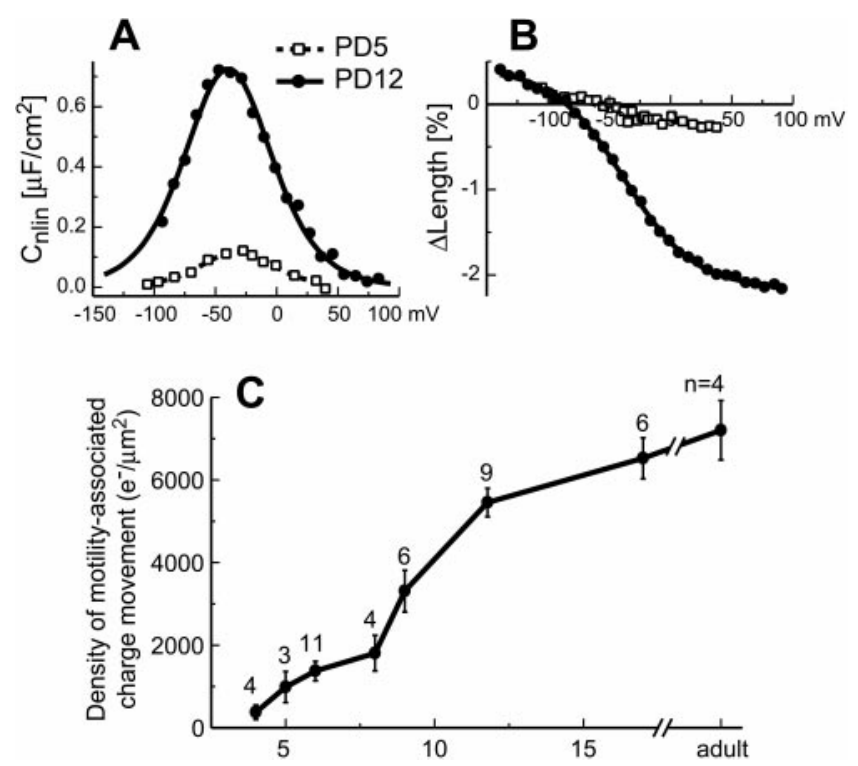

Figure 4. Postnatal growth of the electromotile responses and motilityassociated charge movement in OHCs of the apical turn of the rat's organ of Corti. $A$, Voltage dependence of the specific nonlinear capacitance (in $\mu \mathrm{F} /$ $\mathrm{cm}^{2}$ ) for two sample cells from the apex of the cochlea at PD5 (open squares) and PD12 (closed circles). Data are fit with the derivative of a Boltzmann function. $B$, OHC length changes versus transmembrane voltage in the percentage of the cell length at the holding potential $(-60 \mathrm{mV})$ for the same cells that are shown in $A$. Data are fit with a Boltzmann function. $C$, Density of the motility-associated charge movement $\left(e^{-} / \mu \mathrm{m}^{2}\right)$ versus days after birth (mean $\pm \mathrm{SE}$ ). The number of cells is shown above each point.

mOsm $/ \mathrm{kg}$ (Crist et al., 1993; Ratnanather et al., 1996). The smaller volume changes reduced the potential interference of swellingactivated osmolyte flow. In fact, no significant ion currents were detected in response to the hypo-osmotic challenge. However, our $P_{f}$ values still may be underestimated because the hypo-osmotic 

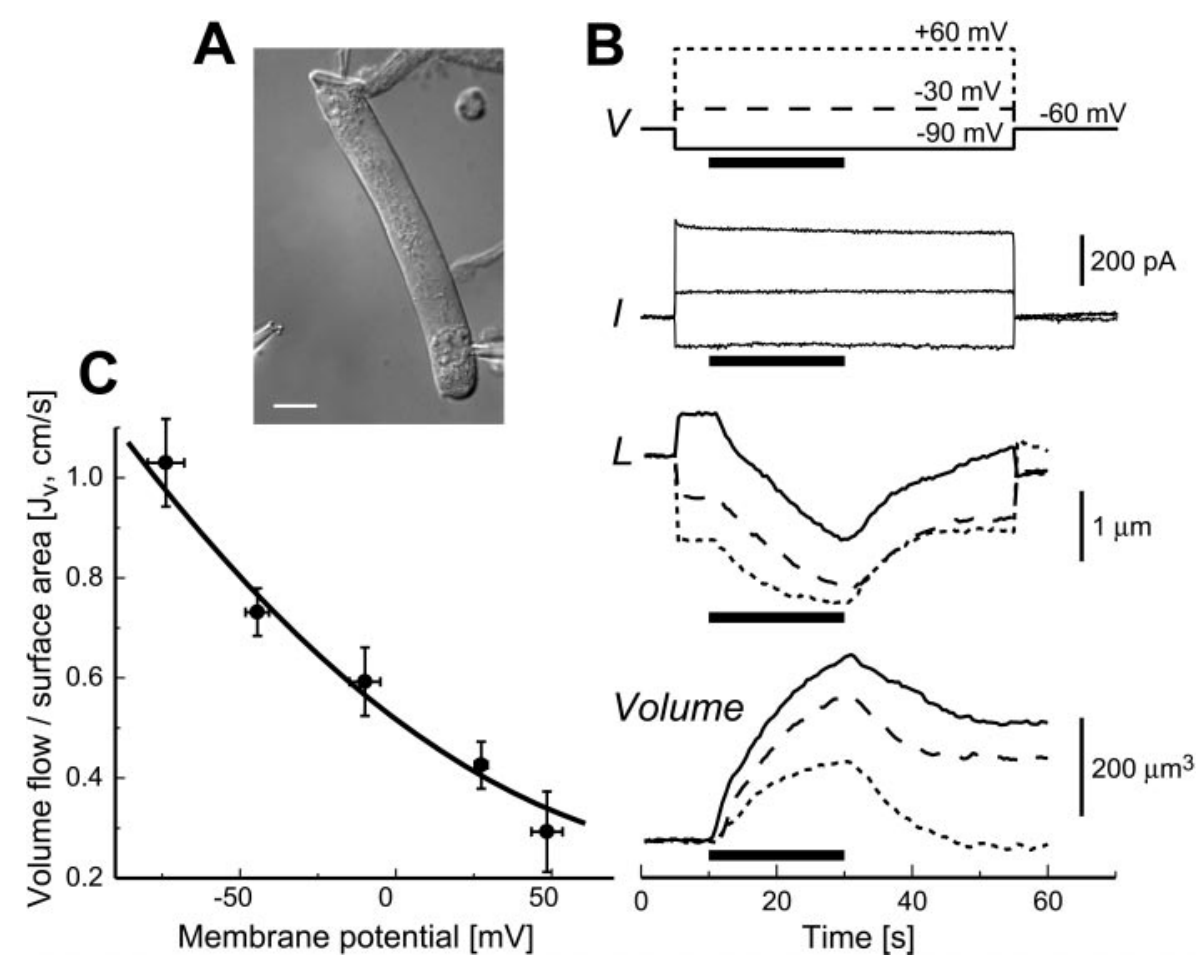

Figure 5. Voltage dependence of water permeability. $A$, Video image of a guinea pig OHC that was patch-clamped at the basal pole with the puff pipette, containing the hypo-osmotic solution, situated $25-30 \mu \mathrm{m}$ from the cell. Scale bar, 10 $\mu \mathrm{m} . B$, Representative data set showing, from top to bottom, voltage steps delivered through the patch pipette $(V$; driving voltages indicated near the traces), whole-cell current $(I)$, length changes $(L)$, and volume changes (Volume). At 5 sec after delivery of a voltage step the cell was subjected to the standard hypo-osmotic challenge $(320 \mathrm{mOsm} /$ $\mathrm{kg}$; solid horizontal bars). Different line types designate length and volume changes at different step potentials: $-90 \mathrm{mV}$, solid lines; $-30 \mathrm{mV}$, dashed lines; $+60 \mathrm{mV}$, dotted lines. $C$, Osmotic water flow $\left(J_{v}\right)$ versus membrane potential. After correction of the potentials for the voltage drop across access resistance, $J_{v}$ measurements in five cells were normalized to the area of the lateral plasma membrane (see Materials and Methods), grouped in $30 \mathrm{mV}$ intervals starting from $-80 \mathrm{mV}$, and averaged. Each point represents the mean $\pm \mathrm{SE}$ $(4 \leq n \leq 5)$. solution delivered through the puff pipette did not bathe the cell uniformly.

\section{Evidence for water channels in the lateral plasma membrane of the OHC}

The values of $P_{f}$ that we obtained for the OHCs $\left(\sim 10^{-2} \mathrm{~cm} / \mathrm{sec}\right)$ are almost one order of magnitude higher than those reported for lipid bilayers, but they are comparable with the values reported for red blood cells $\left(17-25 \times 10^{-3} \mathrm{~cm} / \mathrm{sec}\right.$; Fettiplace and Haydon, 1980). The high $P_{f}$ in red blood cells, like in many other cells, depends on specialized water channel proteins known as aquaporins (Mathai et al., 1996; Verkman et al., 1996). The similarity in the $P_{f}$ values indicates that water channel proteins also may mediate the water influx in OHCs. This conclusion is supported further by the inhibition of $P_{f}$ with $\mathrm{HgCl}_{2}$, which is known to inhibit water transport that is mediated by a number of aquaporins (Folkesson et al., 1994; Verkman et al., 1996). The postnatal developmental changes of $P_{f}$ further indicate that the high $P_{f}$ value in the $\mathrm{OHC}$ is not an intrinsic property of the lipid bilayer of the plasma membrane but results from a progressive incorporation of water channel proteins into the plasma membrane. We also detected by immunofluorescence a protein in the lateral plasma membrane of the OHC that was recognized by a panaquaporin antibody. Because antibodies to known aquaporins did not label the $\mathrm{OHC}$, it is possible that the pan-aquaporin antibody is recognizing a novel form of aquaporin or aquaporin-like protein. The time course of the expression of this protein during postnatal development matches the time course of development of $P_{f}$.

\section{Postnatal development of water permeability and electromotility}

Our data show that the most pronounced developmental changes of $P_{f}$ in the OHCs isolated from the apical turn of the rat cochlea occur between PD11 and PD12. At PD12 the putative water channel proteins recognized by the pan-aquaporin antibody were localized in all of the OHCs along the entire length of the cochlea. The onset of hearing in rats occurs at approximately PD12 (Crowley and Hepp-Reymond, 1966). It is known also that the OHCs from different regions of the cochlea develop differently. Basal OHCs reach adult-like size at $\mathrm{PD} 3$, whereas apical OHCs continue to grow in length up to PD16 (Roth and Volkmar, 1992; Mu et al., 1997). A similar base-to-apex pattern of development was observed in the expression of the putative $\mathrm{OHC}$ water channel proteins. The values of $P_{f}$ obtained for the apical $\mathrm{OHCs}$ reached a plateau at approximately PD16. Thus the time course of the postnatal development of the OHC water transport appears to match the time course of the functional and structural changes in the organ of Corti.

Electromotility is another function of the $\mathrm{OHC}$ that undergoes postnatal development in small rodents like rat and gerbil (He et al., 1994). Here we confirm previous results on the development of motility-associated charge movement in rat OHCs (Belyantseva et al., 1999; Oliver and Fakler, 1999) and extend them to a later postnatal period (up to PD25). Similar to the development of water permeability, the most pronounced changes in the OHC electromotile responses and associated voltage-dependent charge movement were observed before PD12. Thus, our data support the idea that both $\mathrm{OHC}$ water transport and electromotility are critical for the establishment of normal hearing.

\section{What is the mechanism for voltage dependence of the water transport in OHCs?}

Some aquaporins can form voltage-sensitive channels when they are incorporated into a planar lipid bilayer (Ehring et al., 1990, 1992), suggesting that the putative OHC water channel proteins may be regulated by transmembrane voltage. It is also possible that the voltage dependence of water transport is related directly to the mechanism of electromotility. It is presumed that the OHC motor proteins responsible for electromotility are packed densely within the lateral plasma membrane of the OHC (Kalinec et al., 1992). Freeze-fracture images of the OHC lateral plasma membrane revealed an extremely high density of intramembrane particles (Gulley and Reese, 1977; Forge, 1991; Kalinec et al., 1992). The molecular identity of these particles is yet to be determined, but they appear to arrange in regular orthogonal arrays (Kalinec et al., 1992), reminiscent of the orthogonal arrays formed by AQP4 within the plasma membrane of different cells in kidney, brain, and muscle (Verbavatz et al., 1997; Rash et al., 1998). The presence of the water channel proteins among the densely packed and ordered membrane motor proteins potentially may involve lateral proteinprotein interactions. For instance, water channels may sense the local stresses applied to the membrane by the area changes associated with the conformational changes of the OHC motor proteins. 
Alternatively, the mechanism by which voltage affects $J_{v}$ in OHCs may be related to electromotility-induced intracellular pressure changes. Assuming that the permeability coefficient $P_{f}$ does not depend on intracellular potential, the voltage dependence of $J_{v}$ may be explained by the fact that the increased hydrostatic pressure produced by $\mathrm{OHC}$ contraction decreases the osmotic water influx. When the hydrostatic pressure is different between two compartments separated by a membrane, the volume flow across the membrane is (Verkman, 2000):

$$
J_{\mathrm{v}}=P_{\mathrm{f}} \cdot S \cdot V_{\mathrm{w}} \cdot\left[\Delta C+\left(P_{1}-P_{2}\right) / R T\right],
$$

where $P_{1}$ and $P_{2}$ are hydrostatic pressures in these compartments, $R$ is the universal gas constant, and $T$ is an absolute temperature. All other symbols are the same as in Materials and Methods. Therefore, the electromotility-induced changes of intracellular pressure, $\Delta P$, would alter the osmotic volume flow by the value:

$$
\Delta J_{\mathrm{v}}=\frac{P_{\mathrm{f}} \cdot S \cdot V_{\mathrm{w}} \cdot \Delta P}{R T} .
$$

Computations according to this formula and on the basis of the data in Figure 5 give $2.0 \pm 0.1 \mathrm{kPa}(n=3 ; p<0.01)$ as the motility-associated pressure increase per micrometer of cell contraction. These values are compatible with the range of $0.5-1.3 \mathrm{kPa}$ predicted by modeling studies (Dallos et al., 1993) and with the estimated resting turgor pressure $(17 \mathrm{kPa}$; Chertoff and Brownell, 1994). Therefore, when the OHC length decreases in response to depolarization, the increased internal hydrostatic pressure is likely to oppose the osmotic challenge, reducing $J_{v}$ in a voltagedependent manner. Even without osmotic challenge, voltageinduced contraction or elongation of $\mathrm{OHC}$ may change the intracellular pressure and induce volume flow out of or into the cell, respectively. This effect may be responsible, at least in part, for the well known changes of OHC turgor that are observed under sustained hyperpolarization or depolarization (Iwasa, 1996).

\section{Relationship between water permeability and electromotility}

Irrespective of its mechanism, the fact that the water permeability of OHCs is voltage-dependent suggests that there is reciprocity between $\mathrm{OHC}$ turgor and electromotility. Not only can turgor affect $\mathrm{OHC}$ electromotility, but also a sustained depolarization or hyperpolarization may change $\mathrm{OHC}$ turgor. For example, a sustained depolarization induced by humoral factors, such as ATP (Housley et al., 1992), is expected to modulate the water flow across the cell plasma membrane, resulting in slow changes of intracellular pressure. This would cause changes in OHC shape, stiffness, and force production. The modulation of intracellular pressure by transmembrane voltage thus may represent an important feedback mechanism capable of regulating the effectiveness of the $\mathrm{OHC}$ motor output.

In conclusion, the voltage dependence of OHC water transport and electromotility, the timing of their development, and the colocalization of water channel proteins and motor proteins in the lateral plasma membrane suggest that $\mathrm{OHC}$ electromotility and water transport may influence each other structurally and functionally.

\section{REFERENCES}

Beitz E, Kumagami H, Krippeit-Drews P, Ruppersberg JP, Schultz JE (1999) Expression pattern of aquaporin water channels in the inner ear of the rat. The molecular basis for a water regulation system in the endolymphatic sac. Hear Res 132:76-84.

Belyantseva IA, Frolenkov GI, Streett D, Wade J, Kachar B (1999) Is the voltage-driven motor protein for outer hair cell electromotility a member of the aquaporin protein family? In: Abstracts of 22nd Meeting of the Association for Research in Otolaryngology (Popelka GR, ed), abstract 731. St. Petersburg Beach, FL: ARO.

Brown D, Katsura T, Kawashima M, Verkman AS, Sabolic I (1995) Cellular distribution of the aquaporins: a family of water channel proteins. Histochem Cell Biol 104:1-9.

Brownell WE (1990) Outer hair cell electromotility and otoacoustic emissions. Ear Hear 11:82-92.
Butkus A, Alcorn D, Earnest L, Moritz K, Giles M, Wintour EM (1997) Expression of aquaporin-1 (AQP1) in the adult and developing sheep kidney. Biol Cell 89:313-320.

Chertoff ME, Brownell WE (1994) Characterization of cochlear outer hair cell turgor. Am J Physiol 266:C467-C479.

Crist JR, Fallon M, Bobbin RP (1993) Volume regulation in cochlear outer hair cells. Hear Res 69:194-198.

Crowley DE, Hepp-Reymond MC (1966) Development of cochlear function in the ear of the infant rat. J Comp Physiol Psychol 62:427-432.

Dallos P, Evans BN, Hallworth R (1991) Nature of the motor element in electrokinetic shape changes of cochlear outer hair cells. Nature 350:155-157.

Dallos P, Hallworth R, Evans BN (1993) Theory of electrically driven shape changes of cochlear outer hair cells. J Neurophysiol 70:299-323.

Ehring GR, Zampighi G, Horwitz J, Bok D, Hall JE (1990) Properties of channels reconstituted from the major intrinsic protein of lens fiber membranes. J Gen Physiol 96:631-664.

Ehring GR, Lagos N, Zampighi GA, Hall JE (1992) Phosphorylation modulates the voltage dependence of channels reconstituted from the major intrinsic protein of lens fiber membranes. J Membr Biol 126:75-88.

Fettiplace R, Haydon DA (1980) Water permeability of lipid membranes. Physiol Rev 60:510-550.

Folkesson HG, Matthay MA, Hasegawa H, Kheradmand F, Verkman AS (1994) Transcellular water transport in lung alveolar epithelium through mercury-sensitive water channels. Proc Natl Acad Sci USA 91:4970-4974.

Forge A (1991) Structural features of the lateral walls in mammalian cochlear outer hair cells. Cell Tissue Res 265:473-483.

Frolenkov GI, Kalinec F, Tavartkiladze GA, Kachar B (1997) Cochlear outer hair cell bending in an external electric field. Biophys $\mathbf{J}$ 73:1665-1672.

Frolenkov GI, Atzori M, Kalinec F, Mammano F, Kachar B (1998a) The membrane-based mechanism of cell motility in cochlear outer hair cells. Mol Biol Cell 9:1961-1968.

Frolenkov GI, Belyantseva IA, Kachar B (1998b) Electromotility influences the axial stiffness of the outer hair cells. In: Abstracts of 21st Meeting of the Association for Research in Otolaryngology (Popelka GR, ed), abstract 254. St. Petersburg Beach, FL: ARO.

Frolenkov GI, Mammano F, Belyantseva IA, Coling D, Kachar B (2000) Two distinct $\mathrm{Ca}^{2+}$-dependent signaling pathways regulate the motor output of cochlear outer hair cells. J Neurosci 20:5940-5948.

Gale JE, Ashmore JF (1994) Charge displacement induced by rapid stretch in the basolateral membrane of the guinea-pig outer hair cell. Proc R Soc Lond [Biol] 255:243-249.

Gale JE, Ashmore JF (1997) An intrinsic frequency limit to the cochlear amplifier. Nature 389:63-66.

Geleoc GS, Casalotti SO, Forge A, Ashmore JF (1999) A sugar transporter as a candidate for the outer hair cell motor. Nat Neurosci 2:713-719.

Gulley RL, Reese TS (1977) Regional specialization of the hair cell plasmalemma in the organ of Corti. Anat Rec 189:109-123.

He DZ, Dallos P (1999) Somatic stiffness of cochlear outer hair cells is voltage-dependent. Proc Natl Acad Sci USA 96:8223-8228.

He DZ, Evans BN, Dallos P (1994) First appearance and development of electromotility in neonatal gerbil outer hair cells. Hear Res 78:77-90.

Holley MC, Kalinec F, Kachar B (1992) Structure of the cortical cytoskeleton in mammalian outer hair cells. J Cell Sci 102:569-580.

Housley GD, Greenwood D, Ashmore JF (1992) Localisation of cholinergic and purinergic receptors on outer hair cells isolated from the guinea pig cochlea. Proc R Soc Lond [Biol] 249:265-273.

Huang G, Santos-Sacchi J (1993) Mapping the distribution of the outer hair cell motility voltage sensor by electrical amputation. Biophys $\mathbf{J}$ 65:2228-2236.

Iwasa KH (1993) Effect of stress on the membrane capacitance of the auditory outer hair cell. Biophys J 65:492-498.

Iwasa KH (1996) Membrane motor in the outer hair cell of the mammalian ear. Comments Theor Biol 4:93-114.

Iwasa KH, Kachar B (1989) Fast in vitro movement of outer hair cells in an external electric field: effect of digitonin, a membrane permeabilizing agent. Hear Res 40:247-254.

Kachar B, Brownell WE, Altschuler R, Fex J (1986) Electrokinetic shape changes of cochlear outer hair cells. Nature 322:365-368.

Kalinec F, Kachar B (1993) Inhibition of outer hair cell electromotility by sulfhydryl specific reagents. Neurosci Lett 157:231-234.

Kalinec F, Holley MC, Iwasa K, Lim DJ, Kachar B (1992) A membranebased force generation mechanism in auditory sensory cells. Proc Natl Acad Sci USA 89:8671-8675.

Katz U (1995) Cellular water content and volume regulation in animal cells. Cell Biochem Funct 13:189-193.

Macey RI, Farmer RLE (1970) Inhibition of water and solute permeability in human red cells. Biochim Biophys Acta 211:104-106.

Mathai JC, Mori S, Smith BL, Preston GM, Mohandas N, Collins M, van Zijl PC, Zeidel ML, Agre P (1996) Functional analysis of aquaporin-1 deficient red cells. The Colton-null phenotype. J Biol Chem 271:1309-1313.

Mu MY, Chardin S, Avan P, Romand R (1997) Ontogenesis of rat cochlea. A quantitative study of the organ of Corti. Brain Res Dev Brain Res 99:29-37.

Nielsen S, Smith BL, Christensen EI, Agre P (1993) Distribution of the 
aquaporin CHIP in secretory and resorptive epithelia and capillary endothelia. Proc Natl Acad Sci USA 90:7275-7279.

Nobili R, Mammano F, Ashmore J (1998) How well do we understand the cochlea? Trends Neurosci 21:159-167.

Oliver D, Fakler B (1999) Expression density and functional characteristics of the outer hair cell motor protein are regulated during postnata development in rat. J Physiol (Lond) 519:791-800.

Pujol R, Carlier E, Lenoir M (1980) Ontogenetic approach to inner and outer hair cell function. Hear Res 2:423-430.

Rash JE, Yasumura T, Hudson CS, Agre P, Nielsen S (1998) Direct immunogold labeling of aquaporin-4 in square arrays of astrocyte and ependymocyte plasma membranes in rat brain and spinal cord. Proc Nat Acad Sci USA 95:11981-11986.

Ratnanather JT, Zhi M, Brownell WE, Popel AS (1996) Measurements and a model of the outer hair cell hydraulic conductivity. Hear Res 96:33-40.

Roth B, Volkmar B (1992) Postnatal development of the rat organ of Corti. Anat Embryol (Berl) 185:571-581.

Rubel EW (1984) Ontogeny of auditory system function. Annu Rev Physiol 46:213-229.

Santos-Sacchi J (1991) Reversible inhibition of voltage-dependent outer hair cell motility and capacitance. J Neurosci 11:3096-3110.

Shehata WE, Brownell WE, Dieler R (1991) Effects of salicylate on shape, electromotility, and membrane characteristics of isolated outer hair cells from guinea pig cochlea. Acta Otolaryngol (Stockh) 111:707-718.
Stankovic KM, Adams JC, Brown D (1995) Immunolocalization of aquaporin CHIP in the guinea pig inner ear. Am J Physiol 269:C1450-C1456.

Takumi Y, Nagelhus EA, Eidet J, Matsubara A, Usami S, Shinkawa H, Nielsen S, Ottersen OP (1998) Select types of supporting cell in the inner ear express aquaporin-4 water channel protein. Eur J Neurosci 10:3584-3595

Tolomeo JA, Steele CR, Holley MC (1996) Mechanical properties of the lateral cortex of mammalian auditory outer hair cells. Biophys $\mathrm{J}$ 71:421-429.

Uziel A, Romand R, Marot M (1981) Development of cochlear potentials in rats. Audiology 20:89-100.

Verbavatz JM, Ma T, Gobin R, Verkman AS (1997) Absence of orthogonal arrays in kidney, brain, and muscle from transgenic knock-out mice lacking water channel aquaporin-4. J Cell Sci 110:2855-2860.

Verkman AS (2000) Water permeability measurement in living cells and complex tissues. J Membr Biol 173:73-87.

Verkman AS, Mitra AK (2000) Structure and function of aquaporin water channels. Am J Physiol 278:F13-F28.

Verkman AS, van Hoek AN, Ma T, Frigeri A, Skach WR, Mitra A, Tamarappoo BK, Farinas J (1996) Water transport across mammalian cell membranes. Am J Physiol 270:C12-C30.

Zheng J, Shen W, He DZZ, Long KB, Madison LD, Dallos P (2000) Prestin is the motor protein of cochlear outer hair cells. Nature 405:149-155. 